\title{
Optimized Preparation of Urine Samples from Acute Melioidosis Patients for In-Solution Proteomic Studies using LCMS QTOF or MALDI TOF MS
}

\author{
Aniza $\mathbf{P}^{\mathrm{a}}$, M. Yusri Idorus ${ }^{\mathrm{b}}$, Nosrihah Ismail ${ }^{\mathrm{c}}$, Vanitha Mariappan ${ }^{\mathrm{d}}$, Mohammed Imad A. Mustafa \\ Mahmud $^{\text {a }}$ \\ ${ }^{a}$ Dept. of Basic Medical Sciences, Kulliyyah of Medicine, International Islamic University Malaysia Kuantan Campus. \\ ${ }^{b}$ Institute for Medical Molecular Biotechnology, University Teknologi Mara Sg. Buloh \\ ${ }^{c}$ Medical Biotechnology Laboratory, Faculty of Medicine, University Malaya Kuala Lumpur. \\ ${ }^{d}$ Centre of Toxicology and Health Risk Studies (CORE), Faculty of Health Sciences, National University of Malaysia, Kuala Lumpur, Malaysia
}

\section{ABSTRACT}

INTRODUCTION: Investigation of urine proteome in patients with acute melioidosis may reveal potential disease markers, from either bacterial or human proteins. We used an insolution gel-free method instead of 2-DE to detect human and Burkholderia pseudomallei proteins in urine of patients with acute melioidosis. Here, we propose a simpler, economical method for preparing urine samples directly from melioidosis patients, for in-solution proteomic analysis using LCMS-QTOF MS/MS or MALDI-TOF MS/MS. MATERIAL AND METHODS: We adapted an acetone-TCA based protein precipitation method with LCMS-QTOF MS to detect the B. pseudomallei proteins directly from urine of acute melioidosis patients (culture positive and negative). This process involves protein precipitation, desalting, trypsin digestion, and optimization for the mass spectrometry. RESULTS: A total of 3,866 human peptides were detected across 11 urine samples from clinically suspected acute melioidosis patients. Among these, were

Keywords

Burkholderia pseudomallei, biomarker, melioidosis, urine sample, proteomics

\section{Corresponding Author}

Dr. Aniza P. Oothuman,

Dept. of Basic Medical Sciences,

Kulliyyah of Medicine,

International Islamic University Malaysia

Kuantan Campus, Pahang, Malaysia

Tel: +609-571 4000

Email: anizapo@iium.edu.my

Received: 3 March 2021; Accepted: 22 April 2021

Doi: https://doi.org/10.31436/imjm.v20i3 three Burkholderia specific proteins detected in $75 \%$ of culture positive samples. Large amounts of acute phase proteins, cell mediated immunity proteins, complement pathway proteins and inflammatory mediators were seen upon gene ontology (GO) annotation and GO enrichment analysis. CONCLUSIONS: This simple in-solution sample preparation method can be replicated easily for LCMS/MS-QTOF and MALDI-TOF proteomic analyses, avoiding tedious optimization steps in 2-DE. This method is cost effective and can be done in centres without specialized 2-DE or MS equipment and elutes can be easily transported for analysis and bioinformatics. This is the first study to analyse urine samples directly for B. pseudomallei proteins. Discovery of the entire proteome as a whole is important in leading to biomarker discovery.

\section{INTRODUCTION}

Melioidosis is an infection caused by the soil dwelling, Gram-negative bacteria Burkholderia pseudomallei, and it is known to be endemic in Malaysia, Thailand, Northern Australia, and many other tropical and sub-tropical countries. Melioidosis typically causes febrile illness with respiratory symptoms and septicaemia, but also known to cause fulminant fever and severe septicaemia in diabetics, elderly and immunocompromised patients. ${ }^{1}$ The gold standard of diagnosis of melioidosis is still conventional culturing methods. ${ }^{2}$ Polymerase chain reaction (PCR) method is available, however limited to tertiary referral hospitals.
Urine is a complex and diverse source of potential protein biomarker candidates, where the desirability lies with its collection by non-invasive techniques. Urine is the glomerular filtrate of plasma, excretion of cells from the renal tract, and urogenital secretions. They give a dynamic picture of a person's physiologic, pathologic and metabolic state at any given time. ${ }^{3}$ The idea of a urine biomarker to determine severity of disease, prognosis, or efficacy of therapeutics is highly desirable. ${ }^{4}$

Two-dimensional electrophoresis (2-DE) (gel-based proteomics) is a well-established technique; however, it suffers from some ongoing concerns regarding IMJM Volume 20 No.3, July 2021 
quantitative reproducibility and limitations on its ability to study certain class of proteins. With the appearance of MS-based proteomics, new avenues have emerged for quantitative analysis. ${ }^{5}$ In shotgun proteomics (bottom up strategy) complex peptides fractions, generated after protein proteolytic digestion, can be resolved using different fractionation strategies, which offer high-throughput analyses of the proteome of an organelle or a cell type, and provide a snapshot of the major protein constituents. ${ }^{6}$

Previous research on biomarkers of B. pseudomallei involved mostly testing of suitable antigens on culture plate grown bacteria instead of bacterial components derived directly from human samples. ${ }^{7,8}$ Mariappan et al. (2010) studied different cultured isolates of Burkholderia sp. through 2-DE and Western blot analysis and found different immunogenic proteins differently regulated. ${ }^{9}$ Young et al. (2014) have studied urinary bacterial proteins in tuberculosis (TB) patients, and found a panel of 20 human proteins that were significantly different for with and without TB infection. ${ }^{4}$

Thus, this study was aimed to formulate an easier, reproducible method to prepare urine samples from acute melioidosis patients for bottom-up proteomic studies, using either MALDI TOF MS/MS or LCMS QTOF MS/MS. This method can be performed in less equipped laboratories, to then transported to specialized centres for proteomic studies and bioinformatic analysis.

\section{MATERIAL \& METHOD}

\section{Ethics declaration and sample recruitment}

This study was undertaken with ethical approval from Ministry of Health Malaysia's Medical Research and Ethics Committee (MREC), the National Medical Research Register (NMRR) ID: NMRR-16-2699-33554. Informed written consent was obtained from all the 11 melioidosis patients recruited for this study. The patients were diagnosed by clinicians at medical wards Hospital Tengku Ampuan Afzan (HTAA), Kuantan, Pahang (a tertiary teaching hospital). Of the 11 samples tested, eight were culture positive cases (MEL1MEL8) and the remaining were culture negative cases IMJM Volume 20 No.3, July 2021
(NM1-NM3). Some of the patients were recruited upon admission after PCR testing, and some were recruited after being reported as blood culture positive for $B$. pseudomallei. Urine culturing and sensitivity was done for patients in HTAA as part of septic workup, all had no significant findings. Urine culture would not be as sensitive in detecting systemic B. pseudomallei infection unless it was a urinary tract infection.

Clinically suspected cases were recruited using inclusion criteria by physicians in HTAA Kuantan. These were patients who presented with high grade fever with or without respiratory symptoms, with evidence of pneumonic X-ray findings or localized infections, especially those with diabetes and other comorbidities. Mid-stream urine samples of these patients were collected upon admission or upon recruitment into study and the samples were kept cool $\left(-20^{\circ} \mathrm{C}\right)$ until further use. Samples chosen were based on culture result and matching age groups, gender and comorbidities (Table 1). After completion of sample collection, cases were regrouped based on clinical presentation (pneumonic/septicaemic) for analysis purpose only. Grouping was made based on presence or absence of Xray changes.

\section{Urine sample preparation}

Figure 1 shows the step-by-step workflow of methodology in processing urine samples for LCMS/ MALDI TOF MS. ReadyPrep 2-D ${ }^{\circledR}$ clean-up kit, an acetone-trichloroacetic acid (TCA) based clean-up kit was used in this study (BioRad, USA), its ability to concentrate proteins from dilute samples allow higher protein loads for mass spectrometry. The proteins are quantitatively precipitated and concentrated, washing away ionic detergents, salts, nucleic acids, lipids that interfere with protein detection via mass spectrometry.

The protein concentration was quantified using nanospectrophotometer, as the limit of protein concentration for the liquid chromatography mass spectrometry (LCMS) sample preparation was limited to $5 \mu \mathrm{g} / 5 \mathrm{ml}$. The list of protein concentration for each of the above samples is shown in Table 1. Normal protein concentrations can be up to $20 \mathrm{mg} / \mathrm{dL}$. The specific amount of sample to be used was calculated for standardization. 
Table 1: The protein concentrations in urine supernatants of recruited melioidosis patients

\begin{tabular}{|c|c|c|c|c|c|c|c|c|}
\hline Sample & Age & Gender & Diabetes & $\begin{array}{l}\text { Kidney } \\
\text { disease }\end{array}$ & $\begin{array}{c}\text { Culture for } \\
\text { B.pseudomallei }\end{array}$ & $\begin{array}{c}\text { PCR for } \\
\text { B.pseudomallei }\end{array}$ & $\begin{array}{c}\text { Protein } \\
\text { concentration } \\
(\mathrm{mg} / \mathrm{dl})\end{array}$ & $\begin{array}{l}\text { Amount used for } \\
\text { sample preparation } \\
(\mu \mathrm{l})\end{array}$ \\
\hline MEL 1 & 42 & Male & Yes & No & Positive & Negative & $26.53 *$ & 18.9 \\
\hline MEL 2 & 65 & Male & Yes & Yes & Positive & Positive & 18.12 & 27.6 \\
\hline MEL 3 & 52 & Male & Yes & No & Positive & Positive & $21.33^{*}$ & 23.5 \\
\hline MEL 4 & 47 & Male & No & No & Positive & Positive & 20.51 & 24.4 \\
\hline MEL 5 & 44 & Male & Yes & No & Positive & Positive & $21.52^{*}$ & 23.3 \\
\hline MEL 6 & 50 & Male & Yes & Yes & Positive & Negative & $22.73 *$ & 22.0 \\
\hline MEL 7 & 59 & Male & No & Yes & Positive & Positive & $34.08^{*}$ & 14.7 \\
\hline MEL 8 & 54 & Female & Yes & Yes & Positive & Positive & $25.84^{*}$ & 19.4 \\
\hline NM 1 & 65 & Male & Yes & No & Negative & Negative & $29.97 *$ & 16.7 \\
\hline NM 2 & 68 & Female & Yes & Yes & Negative & Negative & $41.67^{*}$ & 12.1 \\
\hline NM 3 & 51 & Female & Yes & Yes & Negative & Negative & $33.39 *$ & 15.0 \\
\hline
\end{tabular}

* above normal protein levels in urine

The urine preparation method according to Kim et al. (2006) was adapted for digesting a complicated protein mixture in absence of denaturants, because LCMS QTOF systems do not allow for detergent (urea) presence in the samples. ${ }^{5}$ Dithiothreitol (DT'T) in $50 \mathrm{mM}$ Tris-HCl ( $\mathrm{pH} 8.0$ ) and iodoacetamide (IAA) in $50 \mathrm{mM}$ Tris- $\mathrm{HCl}$ ( $\mathrm{pH}$ 8.0) were used for the breaking of protein bonds for digestion with trypsin. Prior to adding trypsin, $50 \mathrm{mM}$ Tris- $\mathrm{HCl}$ was added to reduce the concentration of urea to $0.6 \mathrm{mM}$. Then MS grade trypsin was added to the mixture giving a final ratio of $1: 50$ (w/w trypsin:protein). The mixture was incubated at $37^{\circ} \mathrm{C}$ for 18 hours. The digestion was terminated by adding formic acid to a final concentration of $5 \%(\mathrm{v} / \mathrm{v})$.

\section{Desalting process}

Millipore ZipTips ${ }^{\circledR}$ (Milipore, USA) were used as single step desalting, concentration and purification of samples prior to mass spectrometry. The buffers/solvents used were $100 \%$ acetonitrile, $0.1 \%$ formic acid, and $60 \%$ acetonitrile $+0.1 \%$ formic acid. With trial and error while running LCMS, it was observed that the samples had to be eluted four times and then vacuum concentrated to have a good rate of pickup on LCMS QTOF. The sample in quadruplicate was kept at $-20^{\circ} \mathrm{C}$ until ready for analysis using LCMS QTOF MS.

\section{LCMS Run Protocol}

Figure 1 shows the workflow methodology for proteomics analysis carried out in this study. As sample amounts were very small, high recovery LCMS vials were used. The Agilent Zorbax Eclipse ${ }^{\circledR}$ C18 (Agilent, USA) column was used, with smaller column capacity. The normal processing of urine sample was observed to be too dilute for adequate MS/MS peaks to form. Thus, after some troubleshooting runs, we found that quadrupling the sample concentration using Ziptips (four times), the samples were then concentrated by

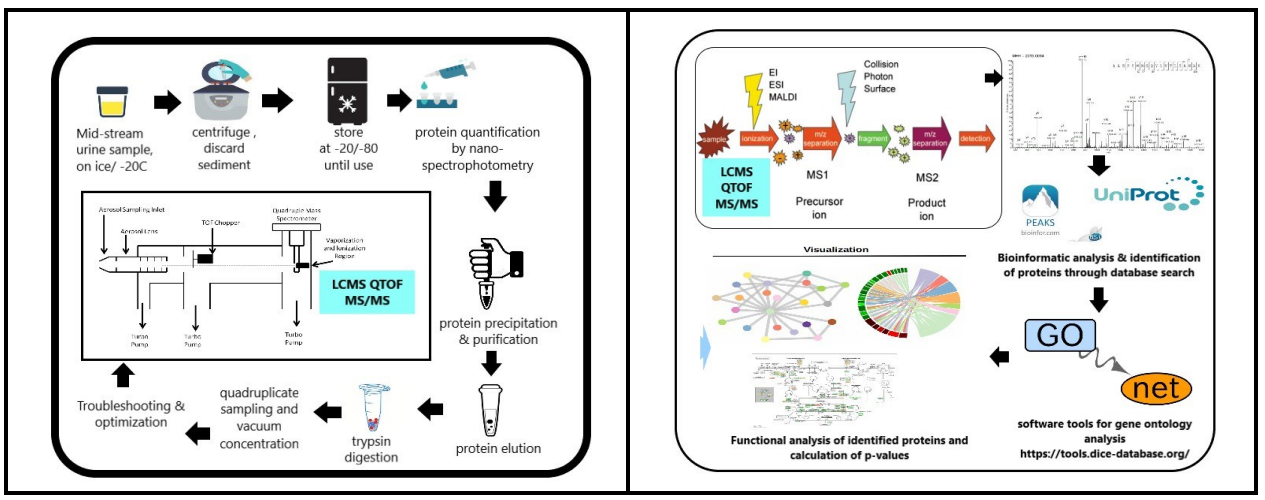

Figure 1: Step by step workflow of processing urine samples for proteomic analysis [image adapted from Young et al. (2014)] Next is the bioinformatics workflow of proteins detected using LCMS QTOF MS/MS for urine samples. LCMS data was analysed using PEAKSX Studio, using uniport.org and SPIDER database of human and B. pseudomallei protein taxonomies. Gene Ontology analysis was done using GO-net.org software tools, as well as generating p-values for identified proteins. 
vacuum drying and then run through LCMS. Instrument used was the Agilent 1200 HPLC-Chip/MS Interface, coupled with Agilent 6550 iFunnel Q-TOF LC/MS (Agilent, USA). Vacuum dried samples were reconstituted with $30 \mu \mathrm{l}$ of Buffer A (water with $0.1 \%$ formic acid).

LCMS settings used in this study were adapted from Gautam et al. (2018) which was optimized for insolution LCMS QTOF experiments, ${ }^{10}$ and also from Juvarajah et al. (2018) using the same LCMS setup locally in Malaysia. ${ }^{11}$ The Agilent Large Capacity Chip was used, (300 Ampere, C18, $160 \mathrm{~nL}$ enrichment column \& 75 um x150 mm analytical column) with a flow rate of $4 \mu \mathrm{L} / \mathrm{min}$ from Agilent 1200 Series Capillary pump and $0.5 \mu \mathrm{L} / \mathrm{min}$ from Agilent 1200 Series Nano Pump (Agilent, USA).

Solvents used were solvent A (water with $0.1 \%$ formic acid) and solvent B (90\% acetonitrile in water with 0.1 $\%$ formic acid.), with the autosampler set at $4^{\circ} \mathrm{C}$. Injection volume was set at $1 \mu \mathrm{l}$, and gradient was set as in Table 2.

Table 2: The runtime protocol used for LCMS QTOF MS/MS

\begin{tabular}{ccc}
\hline Time (min) & $\begin{array}{c}\text { Solvent/ Mobile Phase } \\
\text { A (\%) }\end{array}$ & $\begin{array}{c}\text { Solvent / Mobile } \\
\text { Phase B (\%) }\end{array}$ \\
\hline 0 & 97 & 3 \\
45 & 75 & 25 \\
50 & 60 & 40 \\
51 & 10 & 90 \\
53 & 97 & 3 \\
60 & 97 & 3 \\
\hline
\end{tabular}

Parameters on the Agilent LCMS QTOF MS iFunnel was adapted from Gautam et al. (2018): ion polarity was set to positive, capillary voltage (Vcap) at $1900 \mathrm{~V}$, fragmentor voltage at $360 \mathrm{~V}$, gas temperature $325^{\circ} \mathrm{C}$, drying gas flow 5.0 L/ min. LCMS data was analysed using PEAKS $\mathrm{X}$ database software SPIDER, searching for B.pseudomallei and human taxonomies. ${ }^{10}$ Protein database type search used was Uniprot and TrEMBL (https://www.uniprot.org/) with fixed modification; settings for in-solution and post- translational modification set to carbamidomethylation. The proteins from the GO ID terms were then analysed via bioinformatics web tool (https://tools.dicedatabase.org/GOnet/) to obtain GO enrichment analysis which provides p-values. Database of Immune
Cell Expression, Expression quantitative trait loci (eQTLs) and Epigenomics (DICE), a web-based bioinformatics tool was used to construct interactive graphs containing GO terms and genes conveying the hierarchical structure according to available annotations.

\section{RESULTS}

Following the protocol for sample preparation and protein precipitation as per published methods, the concentration of proteins allowed per run on LCMS was $5 \mu \mathrm{g} / \mathrm{ml}$. This led to a small amount of urine sampled from the initial volume. After a run through the LCMS QTOF, it was found to have very poor signal pickup and unconvincing peaks, with no protein database hits either on LCMS QTOF or MALDI TOF. Hence, there was need for a less dilute initial sample concentration so there is more chance for protein discovery.

After preparing each sample and desalting in quadruplicates, pooling them together and vacuum drying them to a smaller quantity, the subsequent sampling for the LCMS QTOF run picked up good peaks and a large number of proteins, as it also did on MALDI TOF MS/MS.

Table 3 shows the common proteins detected in the culture positive samples, and not seen in culture negative group of samples. Specific proteins noted were namely, peptidoglycan recognition protein 1, cold agglutinin FS-1 L-chain, plasma protease C1 inhibitor, vesicular integral-membrane protein VIP36, pigment epithelium-derived factor, mannan-binding lectin serine protease 2 , and secreted phosphoprotein 1 . The details of these proteins and their functions are as in the Table 4 below.

Three B. pseudomallei bacterial proteins that were consistently detected among $75 \%$ of the culture positive cases via LCMS QTOF MS/MS, namely SDR family NAD(P)-dependent oxidoreductase, 3hydroxyacyl-coA dehydrogenase, and NAD(P)dependent dehydrogenase (short-subunit alcohol dehydrogenase family). However, MALDI TOF MS/ MS database search revealed many uncharacterized Burkholderia sp. proteins. 
Table 3: Common human proteins detected in the urine samples of the confirmed melioidosis cases using LCMS QTOF MS/MS

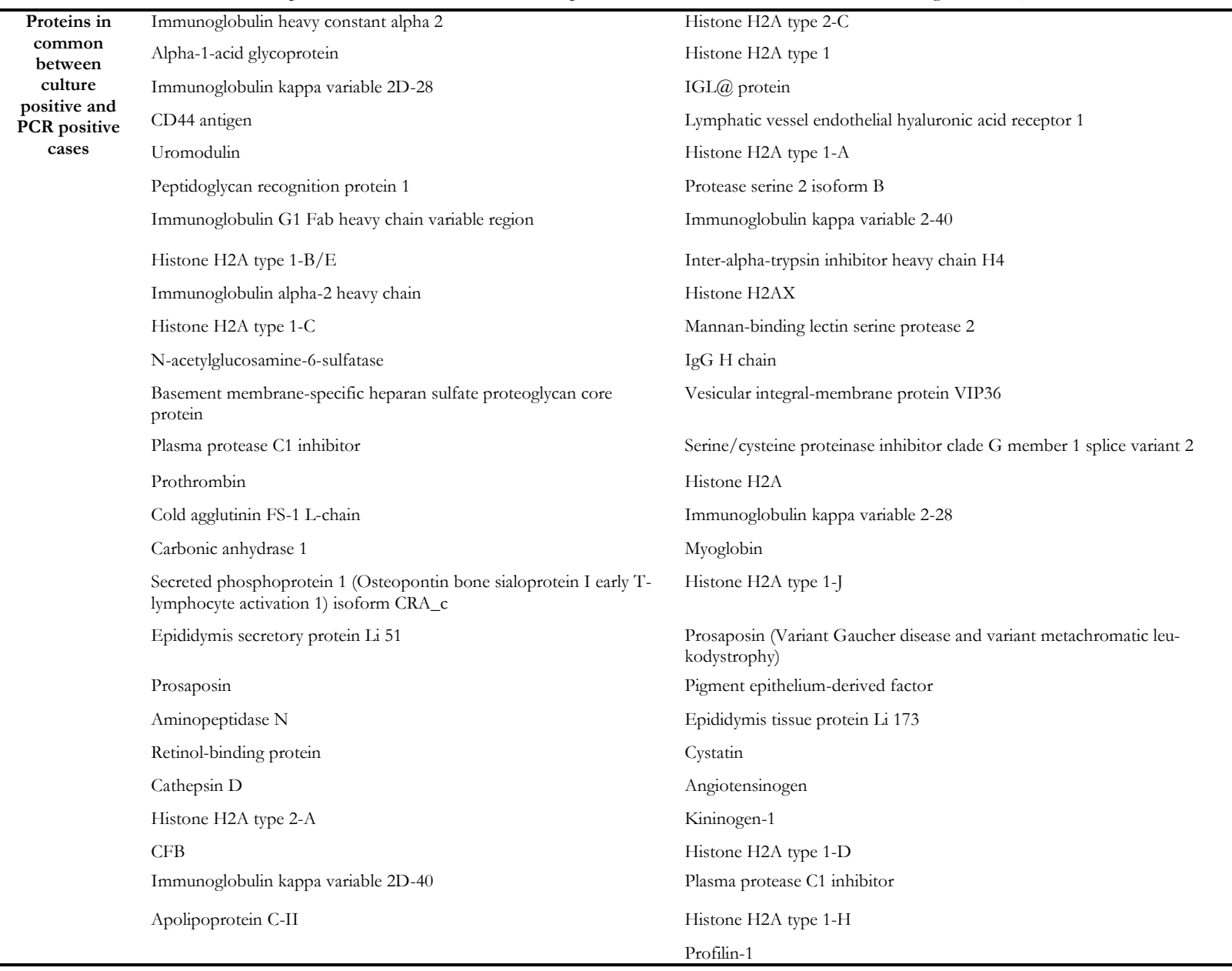

Gene ontology (GO) terms (Figure 2) from the culture positive group showed largest number of proteins groups were involved in immune response, acute phase proteins and defence response proteins. This was consistent with the patients being in the acute phase of infection with flooding of immunological, defence proteins and inflammatory mediators. The next group of proteins were those involved in regulation of normal

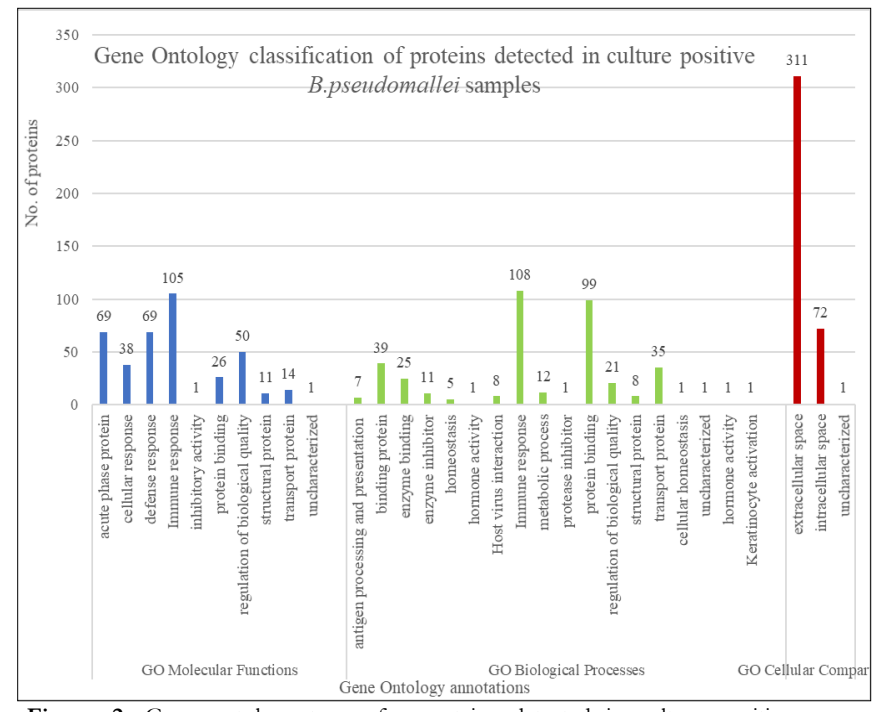

Figure 2: Gene ontology terms for proteins detected in culture positive cases (MEL1-8), divided into molecular functions, biological classes and cellular compartments. (generated using software tools from https://tools.dice-database.org/ GOnet/) biological quality and homeostasis, cellular response proteins, transport proteins and structural proteins. The pattern was similar in the culture negative proteins. Even so, using GO enrichment analysis, the statistically significant human proteins gene ontology terms (with $\mathrm{p}$ value $<0.05)$ are lipoprotein particle remodelling, protein -lipid complex remodelling, myeloid leucocyte mediated immunity, phospholipid efflux, complement activation (classical pathway), humoral immune response mediated by circulating immunoglobulin and others.

P-values were computed using software tools from https://tools.dice-database.org/GOnet/, an online service affiliated to Database of Immune Cell EQTLs, Expression and Epigenomics (DICE) project. The data from PEAKSX was inserted into the pre-programmed software that generated gene ontology analysis and terms.

\section{DISCUSSION}

In-solution gel-free method for preparing urine samples for proteomics has allowed us to skip the optimization 
process of 2-DE and avoid its limitations. Some troubleshooting was required as protein concentrations were too low for detection. Young et al (2014) did suggest the usage of molecular weight cut-off (MWCO) filters, ${ }^{4}$ but due to its unavailability and the concerns on limiting the protein sizes, we opted not to use the MWCO. However, this has caused not only low concentrations of protein, but also masking by high abundance and large sized proteins of smaller proteins

Table 4: Proposed human proteins as biomarkers for acute melioidosis and their functions after comparing between samples from culture positive and culture negative cases

\begin{tabular}{|c|c|c|c|}
\hline No & Protein name & Function & References \\
\hline 1 & $\begin{array}{l}\text { Peptidoglycan } \\
\text { recognition } \\
\text { protein } 1\end{array}$ & $\begin{array}{l}\text { A pattern receptor that binds } \\
\text { murein peptidoglycans of } \\
\text { gram-positive and gram-negative } \\
\text { bacteria, with bacteriostatic activity, } \\
\text { and plays a role in innate immunity }\end{array}$ & Lu et al., $2006^{13}$ \\
\hline 2 & $\begin{array}{l}\text { Secreted } \\
\text { phosphoprotein } \\
1\end{array}$ & $\begin{array}{l}\text { Similar to Osteopontin, although } \\
\text { mostly functioning in bone } \\
\text { remodelling, it also has immune } \\
\text { functions. They are also expressed } \\
\text { in macrophages, neutrophils, T and } \\
\text { B cells, thought to act as immune } \\
\text { modulator with chemotactic } \\
\text { properties }\end{array}$ & $\begin{array}{l}\text { Wang \& Wang, } \\
2008^{14}\end{array}$ \\
\hline 3 & $\begin{array}{l}\text { Plasma protease } \\
\mathrm{C} 1 \text { inhibitor }\end{array}$ & $\begin{array}{l}\text { An acute-phase protein, a protease } \\
\text { inhibitor whose main function is to } \\
\text { inhibit the complement system to } \\
\text { prevent spontaneous activation, but } \\
\text { also as a major regulator }\end{array}$ & $\begin{array}{l}\text { Cicardi et al., } \\
2005^{15}\end{array}$ \\
\hline 4 & $\begin{array}{l}\text { Cold agglutinin } \\
\text { FS-1 L-chain }\end{array}$ & Immunoglobulin-like protein & \\
\hline 5 & $\begin{array}{l}\text { Vesicular inte- } \\
\text { gral-membrane } \\
\text { protein VIP36 }\end{array}$ & $\begin{array}{l}\text { A transmembrane lectin that } \\
\text { shuttles between the endoplasmic } \\
\text { reticulum, Golgi apparatus and } \\
\text { plasma membrane. This protein } \\
\text { binds high mannose type } \\
\text { glycoproteins and facilitate their } \\
\text { activities. }\end{array}$ & $\begin{array}{l}\text { RefSeq,https:// } \\
\text { www.ncbi.nlm. } \\
\text { nih.gov/ } \\
\text { gene/10960, } \\
\text { Oct } 1998\end{array}$ \\
\hline 6 & $\begin{array}{l}\text { Pigment } \\
\text { epithelium- } \\
\text { derived factor }\end{array}$ & $\begin{array}{l}\text { Belongs to a non-inhibitory group } \\
\text { of serpin glycoproteins. Its } \\
\text { biological activities include } \\
\text { promoting cell survival as well as } \\
\text { antiangiogenic, antitumor } \\
\text { properties. Has been touted as } \\
\text { possible prognostic markers for } \\
\text { cancer as well as a potential } \\
\text { therapeutic target }\end{array}$ & $\begin{array}{l}\text { Franco-Chuaire } \\
\text { et al., 201516 }\end{array}$ \\
\hline 7 & $\begin{array}{l}\text { Mannan-binding } \\
\text { lectin serine } \\
\text { protease } 2\end{array}$ & $\begin{array}{l}\text { An enzyme involved in the } \\
\text { complement system; it is involved } \\
\text { in a pathway that reacts to } \\
\text { Ra-reactive (RARF) complement } \\
\text { dependent bactericidal factors. This } \\
\text { factor binds to Ra and R2 } \\
\text { polysaccharides expressed by certain } \\
\text { enterobacteria }\end{array}$ & $\begin{array}{l}\text { Dong et al., } \\
2016^{17}\end{array}$ \\
\hline
\end{tabular}

A simple reproducible gel-free method is valuable in making proteomics more accessible to centres that are not equipped with the very expensive and elaborate equipment. This method can be reproduced in midlevel laboratories without delay and then couriered for further analysis. It also reduces the time needed for optimization as for 2-DE, missed findings in spot picking, and allows for reproducible experiments.
Problems with 2-DE resolution, such as missing high molecular weight proteins (higher than $250 \mathrm{kDa}$ ), masking of low abundance or rare proteins, nondetection of hydrophobic or membrane proteins, can be resolved with gel-free in-solution methods. ${ }^{10}$

Most previous studies in describing proteins expressed or proteome of melioidosis, has been on bacterial culture samples. Mariappan et al (2010) studied stationary phase culture supernatant of B. pseudomallei, using 2-DE and 113 secreted proteins spots we identified. 9 They included metabolic enzymes, transcription/translation regulators, transport regulators. Our sample however, was a direct sample with more human proteins in the mix.

Young et al (2014) analysed urine proteome between definite TB, latent TB, and non-TB cases using SDSPAGE, liquid chromatography, and shotgun proteomic analysis mass spectrometry. They reported 10 different mycobacterial proteins observed exclusively in the urine of definitive TB patients, while six mycobacterial proteins were found exclusively in urine of presumed latent $\mathrm{TB}$ cases. In addition, using $\mathrm{GO}$ enrichment analysis, they identified a panel of 20 human proteins that were significant discriminators for TB disease compared to no TB disease. Seven common human proteins were either differentially over or under expressed in the TB versus non-TB group ${ }^{4}$.

Ward et al from US Army Institute of Infectious Diseases undertook in vivo studies with rhesus macaque animal model, to examine host response to infection using proteomic methods. In comparing with Ebola infected and healthy controls, they found the $B$. psendomallei infected group had expressed 28 unique proteins in altered levels. These proteins were involved in the clotting cascade, immune signalling and complement system activation. ${ }^{12}$

Interestingly our study also showed that a large amount of acute phase proteins, inflammatory proteins, coagulation cascade proteins and immune proteins were detected in the urine along with some bacterial proteins. The urine proteome depicts a dynamic picture of what is happening in the circulation of the body of the patient at the time. This shows a real time 
pathophysiological picture of the infectious process of B. pseudomallei.

Our urine proteomic studies have confirmed the hypothetical findings of animal model studies and highlighted a few potential urinary human protein biomarkers for future studies. Going forward, investigations on bacterial proteins detectable in the serum and sputum of acute melioidosis patients need to be conducted to further identify candidate biomarkers for rapid testing.

\section{ACKNOWLEDGEMENT}

Author would like to thank Professor How and Dr Liyana from IIUM Dept of Internal Medicine for their help in recruiting and procuring of samples for this study. A special thanks to Dr. Roesnita, a microbiologist from HTAA Kuantan, Pahang for providing culture results of patients.

\section{Ethics declaration}

This study was undertaken with ethical approval from Ministry of Health Malaysia's Medical Research and Ethics Committee (MREC), the National Medical Research Register (NMRR) ID: NMRR-16-2699-33554

\section{REFERENCES}

1. How SH, Ng KH, Jamalludin AR, Shah A, Rathor Y. Melioidosis in Pahang, Malaysia. Med J Malaysia. 2005;60.

2. Currie BJ, Dance DAB, Cheng AC. The global distribution of Burkholderia pseudomallei and melioidosis : an update. Trans R Soc Trop Med Hyg [Internet]. 2008;102:S1-4. Available from: http:/ /dx.doi.org/10.1016/S0035-9203(08)700026

3. Thomas CE, Sexton W, Benson K, Sutphen R. NIH Public Access. Natl Inst Heal. 2011;19(4):953 -9 .

4. Young BL, Mlamla Z, Gqamana PP, Smit S, Roberts T, Peter J, et al. The identification of tuberculosis biomarkers in human urine samples. Eur Respir J. 2014;43(6):1719-29.

5. Kim SC, Chen Y, Mirza S, Xu Y, Lee J, Liu P, et al.
A clean, more efficient method for in-solution digestion of protein mixtures without detergent or urea. J Proteome Res. 2006 Dec;5(12):3446-52.

6. Chandramouli K, Qian P-Y. Proteomics: challenges, techniques and possibilities to overcome biological sample complexity. Hum Genomics Proteomics [Internet]. 2009 Dec 8;2009:239204. Available from: https:// www.ncbi.nlm.nih.gov/pubmed/20948568

7. Wongtrakoongate P, Mongkoldhumrongkul N, Chaijan S, Kamchonwongpaisan S, Tungpradabkul S. Comparative proteomic profiles and the potential markers between Burkholderia pseudomallei and Burkholderia thailandensis. Mol Cell Probes [Internet]. 2007 Apr [cited 2016 Apr 28];21(2):81-91. Available from: http:// www.sciencedirect.com/science/article/pii/ S0890850806000582

8. Wongtrakoongate P, Roytrakul S, Yasothornsrikul S, Tungpradabkul S. A proteome reference map of the causative agent of melioidosis Burkholderia pseudomallei. J Biomed Biotechnol. 2011;2011.

9. Mariappan V, Vellasamy KM, Thimma JS, Hashim $\mathrm{OH}$, Vadivelu J. Identification of immunogenic proteins from Burkholderia cepacia secretome using proteomic analysis. Vaccine [Internet]. 2010 Feb 3 [cited 2016 May 4];28(5):1318-24. Available from: http://www.sciencedirect.com/science/ article/pii/S0264410X09017915

10. Gautam SS, Wagh S, Babu S, Gudihal R, Rajagopalan S, Kole P, et al. Relative quantitation of endogenous proteins by quadrupole-time of flight and tandem mass spectrometry. J Chromatogr B, Anal Technol Biomed life Sci. 2019 Feb;1106-1107:11-8.

11. Juvarajah T, Wan-Ibrahim WI, Ashrafzadeh A, Othman S, Hashim OH, Fung SY, et al. Human Milk Fat Globule Membrane Contains Hundreds of Abundantly Expressed and Nutritionally Beneficial Proteins That Are Generally Lacking in Caprine Milk. Breastfeed Med. 2018 Nov;13(9):631 -7 .

12. Ward, M. D., Brueggemann, E. E., Kenny, T., Reitstetter, R. E., Mahone, C. R., Trevino, S., Wetzel, K., Donnelly, G. C., Retterer, C., Jr, R. B. N., Panchal, R. G., Warren, T. K., Bavari, S., \& Cazares, L. H. (2019). Characterization of the plasma proteome of nonhuman primates during 
Ebola virus disease or melioidosis : a host response comparison. Clinical Proteomics, 1-23. https:// doi.org/10.1186/s12014-019-9227-3

13. Lu, X., Wang, M., Qi, J., Wang, H., Li, X., Gupta, D., \& Dziarski, R. (2006). Peptidoglycan recognition proteins are a new class of human bactericidal proteins. Journal of Biological Chemistry, 281(9), 5895-5907. https:// doi.org/10.1074/jbc.M511631200

14. Wang, K. X., \& Wang, K. X. (2008). Osteopontin : Role in immune regulation and stress responses by. https://doi.org/10.1016/j.cytogfr.2008.08.001

15. Cicardi, M., Zingale, L., Zanichelli, A., Pappalardo, E., \& Cicardi, B. (2005). C1 inhibitor: molecular and clinical aspects. Springer Seminars in Immunopathology, 27(3), 286-298. https:// doi.org/10.1007/s00281-005-0001-4

16. Franco-Chuaire, M. L., Ramírez-Clavijo, S., \& Chuaire-Noack, L. (2015). Pigment epitheliumderived factor: clinical significance in estrogendependent tissues and its potential in cancer therapy. Iranian Journal of Basic Medical Sciences, 18(9), 837-855. https://

pubmed.ncbi.nlm.nih.gov/26523216

17. Dong, X., Luo, Y., Gao, Q., Lu, X., Wang, Q., Zhang, Y., Liu, X., Zhang, L., Wang, J., Ma, X., \& Zhu, B. (2016). Effects of MBL-associated serine protease-2 (MASP-2) on liquefaction and ulceration in rabbit skin model of tuberculosis. Microbial Pathogenesis, 99, 282-286. https:// doi.org/10.1016/j.micpath.2016.08.037 